\title{
Unha análise da interacción de aula a través do estudo de caso
}

\author{
Classroom interaction: a case study analysis
}

\author{
Andrea Fernández Sánchez
}

Universidade de A Coruña

\begin{abstract}
Resumen
O presente traballo aborda a cuestión da problemática da interacción profesorado-alumnado no proceso de ensinanza aprendizaxe, mediante unha investigación etnográfica, a través do estudo de caso, levada a cabo nun aula de $6^{\circ}$ de educación primaria, nun centro urbano da cidade de A Coruña. Neste escrito, non se valora unha relación relación específica docente-estudante, nin se trata de facer unha comparativa entre mestres ou de abordar cuestións sobre a calidade e metodoloxía de ensinanza; senón que se trata relatar e determinar cómo o alumnado debería ter o papel principal no proceso de ensino-aprendizaxe.

Palabras chave: interacción de aula, etnografía, proceso ensinanza-aprendizaxe.
\end{abstract}

\begin{abstract}
This communication address the interaction influence in the teaching-learning process, through an ethnography research, especially a case study made in a six grade classroom in a school in A Coruña.

This research is not about a teacher-student relation valuation, neither to compare teachers nor to treat questions about the methodology and education quality. The aim is relate and define how the students should have the principal rol in the teaching-learning process.
\end{abstract}

Que sucede realmente nas aulas? Son moitos os autores que se fixeron esta pregunta e coincidiron na dificultade de dar unha resposta. O interese por comprender, coñecer e mellorar as relacións que se dan na aula débese a que na escola non son só importantes os contidos que se aprenden, senón tamén o modo no que se aprende.

Historicamente, ata aproximadamente os anos 70, concibíase a ensinanza e o aprendizaxe como actividades diferentes (Rivas, 2003). As actividades da ensinanza as promovía o docente para facilitar o aprendizaxe, e o aprendizaxe o realizaba o alumnado coa intención de dominar uns coñecementos, destrezas... Este tratamento diferenciado denomínase binomio ensinanza-aprendizaxe, o primeiro estudado dende o ámbito da didáctica e o segundo da psicoloxía (Rivas, 2003). A Psicoloxía Cognitiva propiciou o tratamento da ensinanza e aprendizaxe como un proceso conxunto, global e interactivo, que finalmente a Psicoloxía da Instrución o concretou como proceso de ensinanza-aprendizaxe. Esta rama da psicoloxía determinou que sobre o binomio ensinanza e aprendizaxe actuaba un elemento, o currículo. Finalmente, determinouse que o o proceso de ensinanza-aprendizaxe estaba formado por tres elementos chave: o profesor, os contidos e o alumno, actuando sempre en triplo interacción e mobilizándose para conseguir unha mesma meta (Rivas, 2003). A base fundamental do proceso de ensinanza-aprendizaxe atópase representada pola relación asociada que existe entre a resposta e o estímulo que a provoca. $\mathrm{O}$ suxeito que ensina é o encargado de provocar dito estímulo, co fin de obter a resposta no individuo que aprende (Edel, 2004).

Tradicionalmente, psicólogos e pedagogos consideraron a interacción profesor-alumno como a máis decisiva para o logro dos obxectivos educativos, tanto dos referidos ao aprendizaxe de contidos como dos que concirnen ao desenvolvemento cognitivo e social (Coll, 1984). Johson (1984 en Rivas 2003) afirma que o énfase da interacción profesor-alumno atopase nas relacións que se establecen entre os alumnos durante o transcurso das actividades de aprendizaxe, e teñen unha influenza secundaria, indesexable ou molesta, sobre o rendemento escolar, pois o elemento decisivo non é a cantidade de interacción senón a súa natureza.

Este último epígrafe lévanos a definir a interacción didáctica, segundo Casado (2010), é o “conxunto de relacións manifestas e latentes que se producen na aula entre os alumnos e os profesores” (p.53), considerándose o proceso de ensinanza-aprendizaxe como eminentemente interactivo. A interacción facilita a comunicación e o intercambio de ideas de profesor e alumnos, converténdose nun compoñente activo da ensinanza. En moitas ocasións dáse por sentado que a interacción na aula é de carácter dialogal, que é "un diálogo o que se desenvolve no salón, e que os estudantes atópanse nun constante intercambio co docente como facilitador e promotor dos procesos de pensamento, amén de transmisor obxectivo de coñecementos" (Velasco, 2007, p.1), deixando sen consideración outros factores igual de decisivos na interacción na aula, os signos non verbais como son os xestos, accións, as actuacións docentes...

Watlawich (1981 en Velasco, 2007) entende que a interacción didáctica é un proceso comunicativo a dobre nivel: Que se di (as actividades organizadas en torno aos contidos) e como se di (o tipo de relacións entre profesores e alumnos en función das expectativas, 
actitudes, valores, necesidades) que enmarcará o proceso de ensinanza-aprendizaxe.

\section{Método}

A presente comunicación circunscríbese na metodoloxía cualitativa, como sinala Ruiz (2007) en relación aos métodos de investigación cualitativa, é máis sinxelo describilos que difinilos. Strauss e Corbin (1990, en Sandín, 2003) entenden por investigación cualitativa "calquera tipo de investigación que produce resultados aos que non se chegou por procedementos estatísticos ou de outro tipo de cuantificación” (p.121), enfatizando o carácter cualitativo a través da información recollida e o seu análise.

As características da investigación cualitativa cambian segundo os métodos circunscritos nesta metodoloxía, é dicir dentro da investigación cualitativa hai unha serie de enforques con características diferenciadas, a etnografía é unha delas. O obxecto da etnografía educativa é "aportar valiosos datos descritivos dos contextos, actividades e crenzas dos participantes nos escenarios educativos” (Sandín, 2003, p.155). Esta centrase en descubrir o que acontece na vida cotiá, aportando datos significativos dun xeito o máis descritivo posible, para máis adiante interpretalos e poder comprender e intervir adecuadamente nas aulas. Os datos obtéñense das interaccións, valores, actividades de todos os participantes, tanto profesores como alumnos, incluso do propio investigador.

\section{Participantes}

Nos estudos etnográficos os medios polos que se levan a cabo a selección das mostras son moi diversas. Hai experimentadores que apoian a súa preselección, é dicir escoller deliberadamente aos suxeitos, para finalmente poder facer unha xeneralización máis ampla. Esta selección pragmática e informada, en lugar do muestreo por probabilidade, débese a que o fin da etnografía non é transferir directamente os resultados dun grupo investigado á poboación, senón comparar e traducir os descubrimentos dese determinado grupo base de estudo.

$\mathrm{Na}$ investigación, seleccionáronse os participantes pragmáticamente, xa que os participantes foran observados durante o Practicum II do Grao de Educación Primaria, de Setembro a Decembro.

Por unha banda atopamos ao alumnado da aula de $6^{\circ}$ de educación primaria, e pola outra ao profesorado da mesma.

Nesta aula conviven alumnos moi diferentes, dende nenos con NEAE, pasando por nenos con pequenas dificultades de aprendizaxe, ata outros cuns intereses máis avanzados aos da súa idade. No tocante as NEAE atopamos a un neno con Síndrome de Down, que xa esgotou as non promocións e actualmente ten unha adaptación curricular significativa do 2ociclo en todas as materias; e unha nena que ten una adaptación curricular significativa do 2o ciclo agás en música.
Tamén hai alumnado con dislexia e trastornos na lectoescritura, TDA e TDAH, así como un neno co síndrome de Klinefelter, que afecta levemente ao seu ritmo de aprendizaxe.

No tocante aos docentes, as súas metodoloxías de ensinanza son moi dicotómicas, ambas participativas, pero unha baseada no diálogo e outra na autoriadade.

O mestre que imparte as linguas, é unha persoa introvertida e perseverante que se caracteriza por ter moita paciencia co alumnado. A interacción co grupo caracterízase polas excesivas interrupcións do alumnado durante as explicacións.

A mestra que imparte matemáticas é esixente e non tolera as faltas de respeto e disrupcións, ten un carácter forte pero ao mesmo tempo paciente. Esta mestra crea un ambiente de aula no que todos poden participar, aínda que ante certos comportamentos incorrectos ou intolerables por parte do alumnado a súa actitude pasa a ser máis autoritaria, para poder controlar ao grupo.

\section{Instrumentos}

Na investigación cualitativa existen varias técnicas de recolección de datos, o seu propósito é obter información dos participantes fundamentada nas percepcións, as crenzas, opinións, significados e actitudes (Vargas, 2012).

Como o obxectivo principal é analizar cómo o alumnado inflúe nas dinámicas de aula, ademais de describir, analizar e determinar cómo as interaccións inflúen na calidade o proceso de ensinanza-aprendizaxe, empregáronse as observacións como principal método de recollida de datos, xa que como sinalan Marshall e Rossman (1989) a observación é “a descrición sistemática de eventos, comportamentos e artefactos no esceario social elixido para ser estudado" (en Kawulich, 2006, p.2). Ademais posibilita obter información sobre un fenómeno tal e como este acontece (Rodríguez, Gil y García, 1999), facilitando e mellorando a comprensión do obxecto de estudo. Seguindo a Stake (1999, p. 62) “a observación cualitativa traballa con episodios de relación única para formar unha historia ou unha descrición única do caso (...) significa atopar bos momentos que revelen a complexidade única do caso”.

Sen embargo, para triangular a información obtida xurde a necesidade de complementar as observacións coas entrevistas aos docentes, como indica Stake (1999, p.63) "moito do que non podemos observar persoalmente, outros xa o observaron ou o están observando", enfatizando a entrevista como ferramenta para obter descricións e interpretacións doutras persoas sobre o caso obxecto de estudo. A través desta coñécese as percepcións dos docentes no tocante a interacción, ademais de implicalos na análise das súas prácticas educativas.

Unha vez recompilados os datos, procédese a codificalos en torno a dous eixes vertebradores, a interacción na aula de matemáticas e na de lingua. 


\section{Resultados}

A partir do análise das observacións e as entrevista podemos enunciar as seguintes conclusións:

1. Tanto o alumnado como o profesorado inflúe no proceso de ensinanza-aprendizaxe ainda que de forma diferenciada; por unha banda o alumnado demanda atención, cunha intensidade diferente en función de cada alumno, e por outra, os docentes coas súas actuacións e respostas determinan canta acción se detrae ao proceso de ensinanza-aprendizaxe pola interacción.

2. O proceso de ensinanza-aprendizaxe está condicionado por todo o alumnado, pero cunha intensidade diferente. Despois de analizar detidamente as observacións, determinouse que de 30 alumnos que compoñían a aula, as interaccións estaban controladas por un grupo de 10 alumnos/as que demandan a constante atención do profesorado da aula; algúns destes alumnos poden variar respecto do docente, pero non defiren moito dun a outro.

3. O proceso de ensino-aprendizaxe está altamente condicionado polo alumnado con NEAE, xa que este é un dos colectivos que demanda unha maior atención e interacción. Esta demanda pode deberse as súas características individuais, con ou sen correlación ao seu déficit, xa que ambos docentes consideran que falando de interacción non existe alumnado con NEAE, senón con características específicas relativas á personalidade do alumnado, e basean as súas respostas e interacción en función desas características específicas. A pesar disto, profesorado ten un tempo específico estipulado para a atención do alumnado con estas características.

4. Ante o alumnado que presenta condutas disruptivas, ambos profesores teñen o mesmo obxectivo, que este alumnado non consiga manexar e influír no ritmo da aula, é dicir no proceso de ensinanza-aprendizaxe. A problemática subxace en que o profesorado non consegue que este alumnado non inflúa, pois demandan tan exponencialmente a súa atención que non saben cómo actuar: interactuan con eles para explicarlles que non o fagan, rífanlles, castíganlles... relegando a un segundo plano ao resto do alumnado e interrompendo a actividade que están a realizar; en definitiva influíndo no desenvolvemento da clase, ou o que é o mesmo no proceso de ensinanza-aprendizaxe.

A diferenza entre ambos docentes é que a mestra de matemáticas aplica sancións máis rápido e ten unha conduta máis estrita na aula, evitando así en maior medida as condutas disruptivas do alumnado, aínda que se seguen a producir. $\mathrm{O}$ mestre de lingua galega que ao ter unha conduta máis democrática e flexible ante o que acontece na aula, provoca que o alumnado presente continuamente condutas disruptivas. Ante estas condutas o mestre amosase pasivo, non adoita nin rifarlles, nin castigalos... senón que ignora o seu comportamento co obxectivo de que non se volva a producir. A actuación da mestra de matemáticas implica unha redución das condutas disruptivas, producíndose en menor medida, polo tanto influíndo menos no proceso de ensinanza-aprendizaxe do resto do alumnado. Sen embargo, a actuación do mestre de galego, aínda que non toma represalias contra ese alumnado influíndo así na dinámica de aula, non fai que as disrupcións sexan menores, polo tanto esas disrupcións séguense producindo e condicionando o proceso de ensinanzaaprendizaxe do resto do alumnado.

5. As quedas de palabra ou atención individualizada, son outros dos factores que inflúen no proceso E-A. Segundo o profesorado, estas interaccións fanse de forma consciente, xa que afirman establecer estas quendas ou a atención individualizada segundo as necesidades individuais do alumnado. Sen embargo, pódese observar que o alumnado que adoita demandar máis atención é o que é atendido prioritariamente.

Finalmente, a través desta investigación pódese concluír que a acción docente condiciona o proceso de ensinanza-aprendizaxe, xa que a interacción docente-alumnado é un elemento inalienable da acción educativa, aínda que este condicionamento non ten porque ser unha problemática, senón que a cuestión radica na calidade da interacción que se produce.

\section{Discusión}

Durante os Prácticum realizados durante o grao ou na propia práctica educativa, estase tan inmersa na vida da aula, axudando tanto aos mestre como aos alumnos, que non hai tempo de fixarse no que acontece realmente na aula. Simplemente fanse accións rutinarias e monótonas durante toda a xornada escolar. Se un neno levantaba a man vaise a atendelo, sen botar unha ollada ao redor por se alguén a pedira antes. Son accións que simplemente se realizan, sen preguntar por qué ou cómo, son acción que xa están programadas.

O mesmo acontece durante as explicacións, estase tan inmersa no que se está a dicir que non paras a mirar as caras do alumnado, se están atendendo ou entendendo o que se di. Podes decatarte que algún se dedica a facer outra cousa no lugar de atender, pero se hai que escribir no taboleiro e explicar, non hai tempo nin forma de analizar o que está acontecendo; so certas sinais poden facer ver que alguén non está entendendo o que se está a dicir. Por exemplo cando o alumno levanta a man ou di o teu nome, so nese intre decátaste que algo acontece.

Ademais as aulas son tan diversas que hai múltiples ritmos de aprendizaxe, se un alumno non entende o que se está a explicar vaise xunto del e dedícaselle máis tempo, mentres os demais fan exercicios ou esperan, condicionando así o ritmo de aprendizaxe de todo o alumnado. $\mathrm{O}$ mesmo sucede cando un grupo de alumnos está a interromper a explicación ou falando sen importarlle o que se esta a dicir, os docentes adoitan empregar técnicas para deter esa interrupción e continuar coa clase, ou ben rifan, calan ata que se decaten ou aplican unha sanción. Do que non nos decatamos é do tempo que se perde por esa interrupción e o tempo que lle deixa de dedicar ao resto do alumnado. 
Este traballo aporta outra perspectiva do que acontece realmente nas aulas e das accións que un mestre realiza de forma automatizada, da a oportunidade de reflexionar sobre condutas que se cree que non están aí, ou que simplemente non se lles outorga a importancia que estes realmente teñen. Como afirma Jackson (1991), para o profesorado, a actividade docente está moi fundamentada na intuición máis que nos procesos de análise reflexivos, mesmo os docentes nunha entrevista chegaron a declarar que a súa conduta na aula estaba determinada por impulsos e sentimentos, máis que por reflexións e pensamentos.

\section{Referencias}

Casado, A. (2010). Aprende a ser maestro. Cuenca: Universidad de Castilla-La Mancha.

Coll, C. (1984). Estrutura grupal, interacción entre alumnos y aprendizaje escolar. Infancia y Aprendizaje, 119-138.

Edel, R. (2004). ICCE: Educación para América. Recuperado el 29 de 05 de 2013 de http://icce.ver.ucc.mx/articulos/articulo_001.php
Jackson, P. (1991). La vida en las aulas. Madrid: Morata.

Kawulich, B. (2006). La observación participante como método de recolección de datos. Forum: Qualitative Social Research, 6(2), Art. 43. Recuperado el 10 de junio de 2015 de http://diverrisa.es/uploads/documentos/LA-OBSERV ACION-PARTICIPANTE.pdf

Rivas, F. (2003). El proceso de enseñanza/aprendizaje en la situación educativa. Barcelona: Ariel.

Ruiz, J.I. (2007). Metodología de investigación cualitativa. Bilbao: Universidad de Deusto.

Sandín Esteban, M. (2003). Investigación Cualitativa en Educación. Fundamentos y tradiciones. Madrid: Mc Graw Hill.

Stake, R. (1999). Investigación con estudio de casos. Madrid: Morada.

Vargas, I. (2012). La entrevista en la investigación cualitativa: Nuevas tendencias y retos. Revista Calidad en la Educación Superior, 119-139.

Velasco, A. (2007). Un sistema para el análisis de la interacción en el aula. Revista Iberoamericana de Educación, 1-12. 